\title{
INTEGRAÇÃO ACADEMIA-SERVIÇO NA FORMAÇÃO DE ENFERMEIROS EM UM HOSPITAL DE ENSINO
}

\author{
ACADEMY-SERVICE INTEGRATION IN THE TRAINING OF NURSES IN A TEACHING HOSPITAL \\ INTEGRACIÓN ACADEMIA-SERVICIO EN LA FORMACIÓN DE ENFERMEROS EN UN HOSPITAL \\ DE ENSEÑANZA
}

\author{
Patrícia Regina de Souza Sales ${ }^{1}$ \\ Maria José Sanches Marin ${ }^{2}$ \\ Carlos Rodrigues da Silva Filho ${ }^{3}$
}

Resumo Este estudo propõe-se a compreender a integração academia-serviço na formação de enfermeiros. Utilizou-se a pesquisa qualitativa e, como referencial de análise, a hermenêutica dialética. Foram respondidos 24 questionários por docentes, enfermeiros assistenciais e estudantes de enfermagem da quarta série do curso de Enfermagem de uma instituição de ensino superior, que conta com um complexo hospitalar certificado como hospital de ensino. Constataram-se a existência de espaços de encontro entre os atores e a construção do conhecimento a partir da prática, possibilitando o desenvolvimento do cuidado individual, coletivo e de gestão. A integração academia-serviço estimula os profissionais do serviço a buscarem conhecimento e pesquisa e contribui para mudanças na prática e no comprometimento dos estudantes. Encontram-se dificuldades pela incompatibilidade das agendas dos docentes e enfermeiros, pouco envolvimento docente com a prática, sobrecarga e despreparo do enfermeiro para o ensino, além da falta de compreensão da equipe multiprofissional quanto ao papel do hospital de ensino. Indicam-se a necessidade de adequação das estruturas e a ampliação dos espaços de diálogo, com maior envolvimento e decisões compartilhadas e, ainda, a qualificação do profissional do serviço. Depreende-se a necessidade de investimentos na qualificação do processo de integração ensino e serviço.

Palavras-chave serviços de integração docente-assistencial; formação de recursos humanos; hospitais de ensino; educação superior; estudantes de enfermagem.
Abstract This study aims to understand the academy-service integration in nursing education. Qualitative surveys were used and dialectic hermeneutics served as an analytical framework. In all, teachers, nursing assistants, and fourth year nursing students of a Nursing course at a college that has a hospital complex certified as a teaching hospital answered 24 questionnaires. What was found was that there are mingling spaces among the players and that knowledge is built from practice, enabling the development of individual and collective care and of management. The academy-service integration encourages service professionals to seek knowledge and research and contributes to changes in practice and to generating commitment among the students. Difficulties arise from the incompatibility in the agendas of teachers and nurses, from the little involvement of the teacher with the practice, from an overload and lack of preparation among nurses for teaching, over and above from a lack of understanding among the multidisciplinary team about the role played by the teaching hospital. There is a need to adapt the structures and expand opportunities for dialog, with greater involvement and shared decision-making and to qualify the service professional. Furthermore, there is also a need for investments to qualify the teaching and service integration process.

Keywords teaching-care integration services; training of human resources; teaching hospitals; higher education; nursing students. 


\section{Introdução}

No contexto de acentuado avanço tecnológico e científico das últimas décadas, se partirmos do princípio de que a atenção à saúde é essencialmente pautada no trabalho humano, a formação dos profissionais torna-se o principal aspecto a ser considerado.

Busca-se na atualidade uma formação que se aproxime dos princípios e diretrizes do Sistema Único de Saúde (SUS), com destaque para a integralidade e para a humanização da atenção à saúde, com ênfase na promoção da saúde, na lógica da vigilância. No entanto, não se pode negar que essa construção caminha na contramão do modelo de cuidado centrado nos aspectos biológicos, na queixa principal e no atendimento à demanda, o que se encontra fortemente arraigado no imaginário dos estudantes, profissionais da saúde e usuários, levando a um descompasso entre o proposto e o que ocorre de fato. Para o enfrentamento dessa situação, é preciso estabelecer uma relação efetiva no sentido de integrar a formação com os cenários de atuação desses profissionais (Feuerwerker e Sena, 1999).

Essa integração vem sendo incentivada desde a década de 1960, por meio do movimento da Reforma Universitária, quando foi proposto articular o ensino e o serviço para a formação de um novo perfil profissional, que fosse adequado às necessidades sociais. Na década de 1970, o Ministério do Trabalho e Previdência Social também enfatizou a importância dessa articulação para a formação, com vistas a se obter um equilíbrio entre a qualidade e a quantidade dos profissionais (Feuerwerker, Costa e Rangel, 2000).

Ao mesmo tempo, na área da saúde, o Movimento da Reforma Sanitária propôs a construção de novos modos de atenção, cujo fundamento principal pautou-se no princípio da integralidade, favorecendo iniciativas de reformulação do sistema de saúde e dos currículos universitários para a formação de profissionais, tendo como estratégia a Integração Docente-Assistencial (IDA) (Feuerwerker, Costa e Rangel, 2000).

O fortalecimento dessas iniciativas deu-se com o advento da Constituição de 1988 ao estabelecer, no artigo 200, que compete ao SUS “ordenar a formação de recursos humanos na área da saúde" (Brasil, 1988). Neste contexto, o Ministério da Saúde assume como função prioritária a formação de recursos humanos para a saúde, com ênfase em profissionais generalistas, com visão humanística e preparados para atuar em um sistema de saúde qualificado e integrado (Brasil, 2005).

A integração academia-serviço está pautada no trabalho coletivo, na pactuação entre estudantes, professores e trabalhadores que compõem as equipes dos serviços de saúde. Tem como foco a qualidade da atenção à saúde individual e coletiva, a qualidade na formação profissional, o desen- 
volvimento e a satisfação dos estudantes, professores e trabalhadores que atuam nos serviços (Albuquerque et al., 2008).

Nos últimos anos, algumas propostas foram desenvolvidas com o objetivo de incentivar e apoiar a articulação academia-serviço de saúde e promover mudanças nos cursos de graduação da área. No início da década de 1990, com o apoio da Fundação Kellog, criou-se o Projeto UNI - Uma Nova Iniciativa na Educação dos Profissionais de Saúde (Kisil, 1996). Em 2001, foi lançado o Programa de Incentivo às Mudanças Curriculares das Escolas Médicas (Promed) como uma proposta de apoio às escolas médicas que queriam adequar seus processos de ensino. Em 2005, o governo federal criou o Programa Nacional de Reorientação da Formação Profissional em Saúde (Pró-Saúde), com a finalidade de reorientar a formação profissional, por meio de uma abordagem integral do processo saúde-doença com ênfase na Atenção Básica e na integração ensino e serviço (Albuquerque et al., 2008). Em 2008, por meio da portaria interministerial n. 1.802, foi instituído o Programa de Educação pelo Trabalho para a Saúde (PET-Saúde), que representa uma importante estratégia de fortalecimento da articulação academia-serviço, com uma estreita relação com as ações do Pró-Saúde.

$\mathrm{Na}$ tentativa de buscar alternativas que pudessem auxiliar na construção desta nova condição, algumas instituições fizeram a reformulação de seus currículos, pois, da forma como estava posto e sedimentado o ensino, não seria possível atender às necessidades de saúde, tampouco inserir no mercado de trabalho profissionais em condições e com capacidade para interferir nas realidades vivenciadas (Silva, 2008).

Frente às necessidades de mudanças no modelo de ensino, visando à formação profissional em conformidade com os mencionados princípios e diretrizes do SUS, passou-se a priorizar como cenário de prática a atenção básica em saúde. No entanto, para avançar nesta construção, é preciso operacionalizar tais princípios nos diferentes níveis de atenção. Desta forma, os hospitais de ensino se conformam em importante elemento na construção dessa nova lógica de atenção.

Na década de 1940 foram construídos vários hospitais de ensino vinculados às faculdades de medicina (Gonçalves, 1982). Em 1974, surge a primeira tentativa de uma política que buscava a aproximação da educação médica com o sistema de saúde, por meio do Convênio Global instituído pelo Ministério da Educação e Ministério da Previdência e Assistência Social (MEC-MPAS). Essa política ganha força em 1977, com o agravamento da crise previdenciária e o surgimento de algumas autarquias, como o Instituto Nacional de Previdência Social (INPS). Já em 1981 ocorre a reorientação da política de saúde, com a implantação das ações integradas de saúde que tinham em seu escopo encontros formais entre as instituições responsáveis 
por atividades de atenção à saúde e as instituições de ensino superior, principalmente as escolas médicas (Brasil, 1987; Brasil, 2007).

Em 1987, já no auge da Reforma Sanitária Brasileira, foi publicada a portaria interministerial n. 15, de 22 de maio de 1987, que estabelecia critérios e parâmetros para a aplicação do Índice de Valorização de Desempenho, exclusivamente para hospitais de ensino, que pautavam estimular estas instituições a promover atividades extramuros, ou seja, levar todo o domínio científico e tecnológico para auxiliar na atenção à saúde (Brasil, 1987).

A Lei Orgânica da Saúde, no artigo 45, procura regular a inserção do hospital de ensino na rede de atenção à saúde (Brasil, 1990).

Já em 2003, os ministérios da Saúde, Educação, Planejamento, Orçamento e Gestão e da Ciência e Tecnologia criaram uma comissão interinstitucional para avaliar e diagnosticar a atual condição dos hospitais universitários e de ensino no país. A missão era reorientar ou reformular a política nacional para essas instituições, a qual se iniciou em 2004. Essa comissão, como resultado do seu trabalho, estabeleceu o Programa de Reestruturação dos Hospitais de Ensino no âmbito do SUS. Em 2007 já estavam contemplados pela nova proposta 213 hospitais em todo o Brasil (Brasil, 2007).

Os hospitais de ensino representam os recursos de saúde mais complexos do SUS, em razão dos grandes investimentos públicos e, ainda, por realizarem os procedimentos mais custosos ao sistema. Para a rede de atenção à saúde, eles são imprescindíveis em razão do desenvolvimento de pesquisa, ensino e da assistência à população. Suas responsabilidades aumentam com o rápido avanço da tecnologia médica, uma vez que realizam a maioria dos atendimentos de alta complexidade (Barata, Mendes e Bittar, 2010).

Fica evidente a importância do hospital de ensino no desenvolvimento da saúde. No entanto, eles apresentam ainda inúmeros problemas que necessitam de uma avaliação mais contundente, pois todo esse processo evolutivo não foi suficiente para garantir uma ancoragem de estratégias que dessem conta da resolução de algumas situações, principalmente as relacionadas à formação, como a criação de uma cultura de articulação entre os processos de ensino e de atenção com vistas aos avanços na direção dos princípios e diretrizes do SUS (Brasil, 2010).

Além disso, escassez e inconsistência das informações sobre a real situação da relação entre o ensino e a prática nos serviços de saúde vêm estimulando a busca por novos conhecimentos. Tal fato mostra que que esta intersecção é fator determinante para que haja ensino de qualidade e que a atenção às necessidades de saúde da comunidade contemplada em todas as suas dimensões (Brasil, 2004).

O contexto da integração academia-serviço, que representa um importante desafio a ser vencido pelas universidades na ressignificação dos processos de ensinar, aprender e atuar, deve ser monitorado por meio de estratégias que possibilitem o direcionamento adequado das ações (Macedo, 2005). Assim, 
justifica-se analisar a integração academia-serviço a partir da percepção dos atores que vivenciam o processo, procurando identificar os avanços e os desafios apresentados na relação academia-serviço e na operacionalização do projeto político pedagógico.

O presente estudo objetivou compreender a integração academia-serviço na formação de enfermeiros, em um hospital de ensino, na visão dos docentes, enfermeiros assistenciais e estudantes de enfermagem.

\section{Descrição do método}

Trata-se de um estudo qualitativo, ${ }^{4}$ o que permite relatar experiências, crenças e expectativas, anunciando novas possibilidades, intenções e projetos. O campo de estudo é o curso de Enfermagem de uma instituição de ensino do interior do estado de São Paulo. Tal instituição conta atualmente com os cursos de Medicina e Enfermagem, além de um complexo hospitalar distribuído em três unidades que funcionam em prédios distintos: o Hospital das Clínicas Unidade Clínico Cirúrgico (112 leitos), o Hospital Materno Infantil (105 leitos) e o Hospital São Francisco (58 leitos). Além disso, conta com Hemocentro, Ambulatório de especialidades, Instituto de Olhos, Unidade de Oncologia. Tal complexo foi certificado pela portaria interministerial n. 2.400/2007 como hospital público e de ensino.

Esses espaços se constituem em cenário de ensino e aprendizagem para os estudantes e, além disso, a instituição mantém parceria com a Secretaria Municipal de Saúde, com vistas a proporcionar a diversificação de cenários e possibilitar a formação de profissionais generalistas com ênfase na atenção básica, conforme proposto pelas Diretrizes Curriculares Nacionais.

No curso de Enfermagem, o projeto pedagógico que começou a ser implementado em 1998 partiu de um perfil profissional que se desejava formar, compreendendo o currículo em uma perspectiva integrada, de forma a favorecer a articulação teoria/prática e trabalho/ensino (Faculdade de Medicina de Marília, 2008).

No curso de Enfermagem desenvolvem-se, ao longo das quatro séries, as seguintes áreas de competência do cuidado à saúde (cuidado individual e cuidado coletivo); da gestão do cuidado e da investigação científica. A estrutura curricular do curso de Enfermagem conta com a Unidade de Prática Profissional (UPP) e a Unidade Educacional Sistematizada (UES). A UES segue a metodologia da Aprendizagem Baseada em Problemas (ABP) e busca oportunizar maior elaboração de processos cognitivos relacionados a situações-problema apresentadas nos diferentes cenários de aprendizagem, e a UPP acontece no cenário real e se utiliza da metodologia problematizadora no seu desenvolvimento (Faculdade de Medicina de Marília, 2008). 
No desenvolvimento dessa lógica curricular, a vivência da prática profissional pelo estudante é considerada uma condição essencial. Para tanto, incentiva-se participação e envolvimento dos profissionais dos serviços como professor colaborador, os quais acompanham os estudantes e integram-se a grupos de educação permanente, visando avançar no movimento de práxis.

O complexo hospitalar conta com 121 enfermeiros assistenciais e 35 docentes de enfermagem, que fazem a interface com os cenários de prática. A população do estudo foi composta pelos 19 enfermeiros assistenciais que voluntariamente atuam como preceptores dos estudantes da quarta série de enfermagem, os quais são denominados pela instituição como professor colaborador, os dez docentes que desenvolvem atividades com os alunos no cenário hospitalar e os 40 estudantes da quarta série do curso de Enfermagem.

Fizeram parte da amostra oito docentes, oito enfermeiros assistenciais e oito estudantes da quarta série do curso de Enfermagem, considerando que, na pesquisa qualitativa, a quantidade de pessoas abordadas deve permitir que haja a reincidência de informações ou saturação dos dados, situação ocorrida quando nenhuma informação nova é acrescentada com a continuidade do processo de pesquisa (Fontanella, Ricas e Turato, 2008). Como critério de inclusão foi considerado que o profissional deveria ter pelo menos dois anos de atuação na instituição, e a amostragem deu-se por conveniência.

A coleta de dados foi realizada nos meses de abril e maio de 2012 e contou com um questionário com questões abertas sobre as atividades que os participantes do estudo desenvolvem por meio da integração academia-serviço, bem como as dificuldades, pontos positivos e sugestões para tal integração. Para aplicação do instrumento, inicialmente foi marcado horário e local com o participante; o pesquisador foi até o local, ocasião em que explicava a finalidade da pesquisa e entregava o instrumento, com o cuidado de proporcionar um local privativo e com condições de o pesquisado responder sem interferências.

As respostas foram emitidas em forma de narrativas escritas, o que permite aos sujeitos relatar experiências, crenças e expectativas, anunciando novas possibilidades, intenções e projetos. A opção pela narrativa escrita deve-se ao seu potencial disciplinador do discurso liberado, permitindo, com maior força, a expressão oral, a compreensão das determinações e limites do vivido (Cunha, 1997). Essa forma de narrativa tem-se mostrado capaz de possibilitar a reflexão sobre a prática, fixar a ação em seu contexto e explicitar a compreensão dos sujeitos envolvidos, permitindo-lhes retomar a experiência vivida (Marcolino e Mizukami, 2008). Para garantir o anonimato dos participantes, as falas citadas foram codificadas (Docente: D; Estudante: E; Enfermeiro Assistencial: EA) e, na sequência, numeradas de acordo com a ordem de realização. 
A análise dos dados resultante das narrativas dos sujeitos pautou-se na hermenêutica dialética, pela possibilidade de compreender os fenômenos na sua complexidade e historicidade (Ayres, 2005).

O método de análise da hermenêutica dialética é descrito como uma forma de reflexão, um caminho do pensamento, que tem como norte a aproximação com a práxis social, aprofundamento na práxis histórica, social, econômica e política, na busca de uma visão de totalidade para a compreensão do fenômeno. Nesta perspectiva, compreende-se que o investigador deve imergir no texto na busca de desvelar o que ficou inconsciente para o autor, bem como criar relevâncias e acrescentar conhecimento novo (Minayo, 2001).

Nesta trajetória, mediante a obtenção das narrativas dos participantes, elas foram transcritas pela própria pesquisadora em um quadro, o que permitiu a visualização dos dados por participante de acordo com as questões realizadas e foi considerado como o momento de encontro com os fatos empíricos e ordenação dos dados. Num segundo momento, considerado como o de 'classificação dos dados', que consiste em compreender que os dados não existem por si só, mas são construídos a partir de questionamentos sobre eles, com base nos fundamentos teóricos, foram identificadas as estruturas relevantes das narrativas dos participantes, as quais foram agrupadas em núcleos de sentido. Por fim, 'a análise final', momento em que se estabeleceu a articulação entre os dados coletados e os referenciais teóricos da pesquisa, num movimento dialético que considera a divergência, a contradição, o concreto e o abstrato, o particular e o geral, visando chegar ao concreto pensado (Minayo, 2004).

A proposta de investigação foi aprovada pelo Comitê de Ética em Pesquisa com Seres Humanos da Faculdade de Medicina de Marília (Famema), parecer n. 178/12. Os participantes foram informados sobre a finalidade do estudo e, quando de acordo em participar, assinaram o termo de consentimento livre e esclarecido.

\section{Apresentação dos resultados e sua discussão e avaliação por núcleos de sentido}

Com base nas respostas dos participantes às questões abertas e pautando-se no referencial da hermenêutica-dialética, foram elaborados quatro núcleos de sentido que indicam a estrutura da integração academia-serviço realizada em um hospital de ensino, bem como suas potencialidades, dificuldades e sugestões.

Núcleo de sentido 1 - Na estruturação das atividades evidencia-se a existência de espaços de encontro entre os diferentes atores, a construção do conhecimento a partir das vivências da prática profissional e a possibilidade de desenvolver o cuidado individual, coletivo e de gestão. 
Na descrição dos participantes observa-se que, pela forma como as atividades estão organizadas, existe a possibilidade de se desenvolver uma prática articulada entre os diferentes atores, uma vez que há encontros semanais entre estudante, docente e enfermeiro assistencial. Além disso, nesses encontros, as discussões são pautadas nas vivências dos estudantes no cotidiano do serviço, levando à troca de saberes e encaminhamentos em prol de novas formas de intervir na realidade dos serviços.

Estabeleço uma relação ética e cooperativa com o aluno a fim de que o mesmo possa desenvolver-se e ampliar seus conhecimentos; esclareço suas dúvidas dialogando as práticas vivenciadas de forma que o estudante construa seu conhecimento; observo as ações em relação ao cuidado (...) verificando seus conhecimentos e estimulando o aluno a pensar com intuito de ampliar seus conhecimentos e ter visão crítica da situação vivenciada (EA7).

Na UPP 4, o momento da supervisão possibilita um movimento de integração academia-serviço, a presença do enfermeiro permite refletir o processo de cuidado e o desenvolvimento do desempenho do estudante (D8).

Realizo todas as funções do enfermeiro, junto à enfermeira assistente, tentando entender o funcionamento da ala e quais são os serviços da enfermagem e da gestão. Participo das reuniões de gestão junto com a enfermeira gerente da unidade. Realizo procedimentos junto à enfermeira assistente e discussões de caso e assuntos necessários para agregar ao conhecimento da ala (E1).

Revela-se que, no movimento de reflexão sobre a prática exercida pelo enfermeiro e vivenciada/compartilhada pelo estudante, ocorre a ampliação do conhecimento nas discussões, acrescida das buscas conceituais que embasam a ação profissional. Desta forma, caminha-se em conformidade com os princípios da prática problematizadora, a qual assume "a construção do conhecimento como traço definidor da apropriação de informações e explicação da realidade, tomando-a como ponto de partida e chegada do processo de aprendizagem" (Batista et al., 2005).

Estudo sobre uma experiência de integração academia-serviço descreve que os estudantes vivenciaram o cotidiano dos trabalhadores, participaram de reuniões de equipe, visitas domiciliares e outras rotinas do serviço para diagnosticar situações-problema e desenvolver o planejamento estratégico situacional. Para os autores, a experiência auxiliou na formação crítica dos estudantes, que também contribuíram para o enfrentamento dos problemas juntamente com a equipe (Vendruscolo, 2010).

Na mesma direção encontram-se as ideias de Paulo Freire, quando afirma que o conhecimento é desenvolvido só por meio da ação do indivíduo. 
(Freire, 2006). Isso faz com que a aprendizagem se torne significativa e duradoura, que o discente adquira o desejo de aprender e se torne estimulado a produzir o próprio conhecimento.

Nesta perspectiva, a atividade escolar é pautada na realidade social imediata, na qual se analisam os problemas e seus fatores determinantes e estrutura-se uma atuação com intenção de transformar a realidade social e política. A escola passa a ser o local de problematizar a realidade, e a decisão do que saber e do que fazer está na dependência das necessidades sociais vividas. Define-se, assim, que a prática deve se basear em leis teóricas, em um movimento de ação-reflexão-ação, tendo como fim contínuas possibilidades de transformar a realidade (Feuerwerker, 2002).

Além dos encontros semanais entre estudantes, enfermeiros assistenciais e docentes, os participantes do estudo também descrevem, como atividade da integração academia-serviço, a educação permanente, que é realizada quinzenalmente com docentes e enfermeiros assistenciais. Nesses encontros, conforme apontado, são discutidos assuntos referentes a novos conceitos e conteúdos, às metodologias de aprendizagem e à avaliação do estudante.

Dentre as atividades que desenvolvo, tentando focar a integração ensino-serviço, destacam-se: participação da EP com ensino e serviço; levo, discuto e apresento conceitos/conteúdos novos e atuais aos enfermeiros supervisores (D3).

A educação permanente quinzenalmente; onde professores colaboradores e docentes direcionam discussões voltadas para a metodologia de ensino-aprendizagem no qual a instituição está inserida (EA2).

A instituição de processos de educação permanente vem ao encontro das políticas públicas de saúde, ao considerar a necessidade de mudanças no atual modelo de atenção, uma vez que, para intervenções efetivas na realidade, é preciso considerar a diversidade e a complexidade existentes nos diferentes contextos de trabalho.

A política nacional de educação permanente permeia a aprendizagem no cotidiano do trabalho, ou seja, o aprender e o ensinar se incorporam na organização do trabalho, e a educação, portanto, não pode estar desvinculada do mundo do trabalho na saúde (Brasil, 2009).

Na proposta de integração academia-serviço que ora se analisa, os participantes revelam que desenvolvem ações de cuidado individual, coletivo de gestão, o que indica que eles se aproximam do real papel do enfermeiro enquanto profissional inserido na equipe de saúde, conforme segue:

As atividades são desenvolvidas nos âmbitos individuais, coletivos e de gestão. São realizadas visitas de enfermagem, coleta de dados primários, exame físico, evolução 
de enfermagem, sendo necessária a associação do conteúdo teórico. Realiza-se divisão dos auxiliares, elaboração de escala, divisão dos funcionários por leitos (E2).

As atividades descritas pelos participantes, no entanto, refletem a intencionalidade da integração academia-serviço e, em certa medida, a sua estruturação. Por outro lado, ao solicitar aos participantes que abordassem as potencialidades, dificuldades e sugestões, foram apreendidos novos significados que mostram, principalmente, como se dá o processo de desenvolvimento das mesmas.

\section{As potencialidades da integração academia-serviço}

Núcleo de sentido 2 - A integração academia-serviço estimula os profissionais do serviço a buscarem novos conhecimentos e pesquisar, contribui para mudanças na prática e para o amadurecimento e comprometimento dos estudantes com o local de atuação.

Frente às contribuições que os participantes do estudo explicitam sobre a integração academia-serviço, depreende-se a existência de importantes acréscimos para a transformação da prática e da formação profissional, conforme as narrativas que seguem:

Contribui para a melhora da prática, tendo em vista que, participando da elaboração de problemas e planejamento estratégico as docentes do cenário da prática, conseguem melhores resultados no processo de trabalho. Estimula a pesquisa para os professores colaboradores (E3).

A inserção dos alunos na unidade para atividades de prática profissional contribui positivamente com o amadurecimento dos mesmos, com a organização do setor, trabalho em equipe e o compromisso de todos envolvidos com o processo ensino-aprendizagem desses discentes (EA3).

Integração academia-serviço contribui para a melhora da prática, tendo em vista que, participando da elaboração de problemas e Planejamento Estratégico (...), conseguem melhores resultados no processo de trabalho (E19).

Outro estudo que analisou a experiência de integração academia-serviço também indica que ela traz contribuições tanto para o serviço como para a formação profissional e comunidade assistida, na medida em que melhora a qualidade da atenção à saúde. Acrescenta que a problematização da prática levou à compreensão do significado do contexto intercultural no trabalho em equipe multiprofissional e das representações do conceito de saúde/doença que permeiam o contexto de atenção à saúde (Mestrini Júnior et al., 2011). 
Na mesma direção aponta-se que o ensino pautado na realidade permite a construção de parâmetros éticos nas relações cotidianas, incluindo respeito, justiça e solidariedade. Mostra-se desta forma a existência de relações positivas e que a integração academia-serviço depende inteiramente desta condição (Brasil, 2004).

Referindo-se às vantagens da integração academia-serviço, outros estudos indicam que os estudantes aplicaram as ferramentas do Planejamento Estratégico Situacional (PES), resgataram o controle social, evidenciando-se a união de esforços e melhora no processo de trabalho (Mestrini Júnior et al., 2011).

Tiveram a oportunidade de conhecer a realidade da população e planejar as ações e intervir em conjunto com a equipe, o que contribuiu para uma aprendizagem significativa e para o reconhecimento da importância dessa prática no contexto dos serviços de saúde (Moimaz et al., 2010). Descreve-se, ainda, que houve fortalecimento das relações de parceria entre a instituição formadora, os profissionais, gestores e usuários; ampliação da oportunidade de desenvolver e aperfeiçoar habilidades de cuidado, educação, gerência e pesquisa, a partir da realização das atividades assistenciais junto à comunidade, família e indivíduos (Lima, 2009).

Na integração academia-serviço desenvolvida no hospital de ensino em tela, também foram relatadas importantes dificuldades que precisam ser analisadas, com vistas ao aperfeiçoamento do processo.

\section{As dificuldades da integração academia-serviço}

Núcleo de sentido 3 - Na integração academia-serviço encontram-se dificuldades em compatibilizar as agendas, pouco envolvimento docente com a prática, sobrecarga e despreparo do enfermeiro para atuar no ensino, além de falta de compreensão da equipe multiprofissional quanto ao papel do hospital de ensino.

As dificuldades apontadas perpassam condições semelhantes ao que foi encontrado em outros estudos. Como exemplo disso cita-se que, apesar do discurso referente à necessidade de transformação da realidade presente tanto nos atores dos serviços como da academia, ainda existe um distanciamento entre eles para se atingir um objetivo comum (Colliselli et al., 2009). A fala seguinte ilustra tal semelhança:

Percebo ainda pouca comunicação entre profissionais, docentes e estudantes, além de práticas desconexas que, ao invés de serem compartilhadas e somadas para melhoria do cuidado e formação, são utilizadas apenas para objetivos próprios (EA13).

A esse respeito, acrescenta-se que tal distanciamento decorre da verticalização dos processos, uma vez que o saber acadêmico, muitas vezes, subestima 
a prática como fonte de conhecimento e, por outro lado, a prática desconsidera o potencial do conhecimento acadêmico para a reflexão crítica sobre o fazer (Colliselli et al., 2009).

Falta de comunicação entre os docentes e professores colaboradores (...). Desacordo em relação a conteúdos abordados e sua significância no momento de aprendizagem para o estudante (EA10).

Um dos maiores problemas a ser superado é a sobrecarga de serviço de enfermeiros, que muitas vezes não acompanham os alunos para que o serviço não se acumule (E18).

Neste contexto, analisa-se ainda que a implementação da integração academia-serviço é dificultada pelas políticas e estruturas dos serviços; os docentes distanciam-se das situações práticas do cotidiano e passam a intensificar a teoria e os profissionais da assistência envolvem-se com as atividades do trabalho deixando de se atualizarem cientificamente (Caetano, Diniz, Soares, 2009).

Encontra-se também a passividade dos serviços diante da academia como produtora do saber (Morais et al., 2010). No presente estudo, embora tenham sido definidas algumas condições para o desenvolvimento da integração academia-serviço, questões estruturais impedem que ela ocorra a contento, como se observa na descrição a seguir.

Nesse momento, seria necessário pensar na dificuldade de compatibilizar as agendas da graduação com o serviço, para favorecer a participação dos diversos atores envolvidos nas atividades propostas (D1).

Outro aspecto relatado como uma das dificuldades para integração academia-serviço é o pouco envolvimento do docente nas atividades de prática, o que se observa nessa descrição: “Maior inserção do docente no serviço assistencial" (D2).

Em análise da integração academia-serviço em cenários que recebem estudantes de diferentes áreas da saúde, evidenciou-se que as ações desenvolvidas pelos docentes resumem-se a prestar assistência, distribuir tarefas, supervisionar a prática e acompanhar os alunos, não existindo, portanto, movimento de complementaridade, o que seria adequado a um bom desenvolvimento da integração academia-serviço. Mesmo assim, os autores afirmam que o bom vínculo entre profissionais e docentes contribuiu para a integração (Lobo et al., 2010).

Entre as dificuldades relatadas também se encontram aquelas relacionadas à falta de preparo dos profissionais do serviço para as atividades didáticas, conforme se observa nas descrições seguintes: 
Dentro da minha prática, inclusive, percebo que as professoras colaboradoras sentem que chegamos despreparados para o cenário. Além do que, sinto que muitas não conhecem a metodologia ativa da instituição, o que explica não entender e questionar como chegamos ao quarto ano sem algumas informações as quais elas consideram primordiais (E19).

Problemas com o enfermeiro supervisor (...) muitos são despreparados do ponto de vista didático, sendo que assim seria necessária uma capacitação dos enfermeiros para conhecer melhor o método da faculdade (E24).

Esse aspecto pode estar relacionado com a afirmação de que os profissionais do serviço participam pouco do planejamento, seja no desenvolvimento ou na avaliação das atividades do Estágio Curricular Supervisionado, destacando-se a necessidade de fortalecimento das ações colaborativas, tanto do docente quanto do enfermeiro assistencial, pois ambos são atores do processo de aprendizagem, tanto na supervisão do estudante como no desenvolvimento das atividades (Pereira, Fracolli, 2011).

Também se observa nas descrições dos participantes a dificuldade da equipe em considerar ensino e assistência como condições interdependentes.

Maior compreensão da equipe em geral, que esta instituição é um hospital-escola

e, consequentemente, um ambiente onde os alunos têm a oportunidade de atuar, e assim entender que o aluno está em processo de formação (E21).

Esta dificuldade também é relatada em estudo que afirma que os hospitais universitários, mesmo com a missão de ensino, assistência e pesquisa, priorizam a eficiência assistencial, e que cabe ao gestor da unidade de serviço a responsabilidade de articulação de dimensões, por vezes, conflituosa (Lobo et al., 2010).

\section{As sugestões para a integração academia-serviço}

Núcleo de sentido 4 - Para melhoria da integração academia-serviço sugerem-se adequação estrutural e ampliação dos espaços de diálogo, maior envolvimento dos atores nos distintos cenários e decisões compartilhadas, capacitação e valorização do profissional do serviço, além da definição de um único referencial de cuidado.

As sugestões apontadas, portanto, implicam mudanças estruturais nos processos de trabalho e nos referenciais epistemológicos do cuidado, envolvendo tanto a macro como a micropolítica, conforme se observa nas narrativas que se seguem: 
Cobertura de outro enfermeiro na unidade para que possamos participar da EP, porque em vários dias não podemos participar dos encontros por falta de cobertura na unidade, um local apropriado para as conversas, discussão de casos e realizar o levantamento do problema; melhorar as relações entre os membros da equipe (EA15).

Para mim, a superação passa pela elaboração de um projeto de cuidar único, realizado pelos gestores, preceptores e docentes, no qual explicita a atribuição/contribuição das partes. Para tanto, deve-se pactuar uma política de gestão participativa e o modelo assistencial a ser instituído nos serviços. Também um empenho dos serviços e da academia em qualificar os profissionais (preceptores e docentes) para além das atividades de educação permanente (D8).

Maior inserção do docente no serviço assistencial; capacitação dos enfermeiros para receber o estudante; melhor incentivo financeiro, contratando os enfermeiros supervisores como assistentes de ensino; melhorar o valor financeiro da UPP; valorização do enfermeiro; utilizar um único referencial para condução da assistência que possibilite sua aplicação na prática (D5).

Frente a tais sugestões, é importante refletir sobre o quanto os gestores dos serviços públicos de saúde, regidos pelos princípios e diretrizes do SUS, estão despertos para a prerrogativa de que este espaço representa também um local privilegiado para o ensino contextualizado e transformador da realidade. E que, ao fazer gestão do serviço, está implícita a incorporação da academia em seus processos. Para tanto, há que se pensar, inicialmente, no espaço físico para a operacionalização da proposta, pois embora este aspecto por si só não garanta que o processo ocorra de forma adequada, ele é condição essencial e representa o primeiro passo quando se deseja a melhoria das condições de trabalho/ensino.

No nível macro, a decisão principal compreende a alocação de recursos suficientes para a expansão e a qualificação dos serviços. No nível micro, deve-se investir e acompanhar os processos de trabalho referentes às ações de expansão e melhoria dos serviços, reforçando o fortalecimento da participação, como ação inerente aos processos de trabalho (Souza, 2009).

Acrescenta-se que para intervir no nível micro é preciso uma lógica de gestão que coloca os seus construtores em reflexão e aprendizagem, considerando que processos coletivos e participativos implicam corresponsabilização dos atores envolvidos no ato de cuidar (Malta e Merhy, 2010).

Nesta perspectiva, para que haja a consolidação das práticas de integração academia-serviço, é preciso transformar o processo de trabalho. Também é necessária a coerência entre o projeto dos serviços e a proposta educativa, em suas dimensões política, técnica e metodológica, com o en- 
volvimento de gestão dos serviços de saúde, da universidade e da população (Pereira e Fracolli, 2011).

Assim como no presente estudo sugere-se, para o fortalecimento da parceria, a participação dos profissionais do serviço em cursos de qualificação docente e apoio às questões de infraestrutura (Caetano, Diniz e Soares, 2009).

\section{Considerações finais}

O presente estudo apresenta aspectos da integração academia-serviço de um curso de enfermagem que desenvolve atividades de prática profissional em um hospital de ensino, e embora trate de uma situação específica, os resultados obtidos se aproximam dos encontrados em outros estudos que também relatam tal experiência.

Quanto às ações desenvolvidas em prol da integração academia-serviço, estão pautadas nas atividades estruturadas em conformidade com as orientações para mudanças das práticas de atenção à saúde e de formação profissional, evidenciadas pelos espaços de encontro entre os diferentes atores, com ênfase na problematização da prática profissional e no desenvolvimento da educação permanente como uma ferramenta primordial na efetivação das relações entre os atores dos distintos cenários de atuação.

Com relação aos aspectos positivos, o que ficou evidente na fala dos participantes da pesquisa está relacionado à sua contribuição para a qualificação da prática e da formação profissional, uma vez que estimula a busca de novos conhecimentos e o interesse por pesquisa entre os profissionais do serviço, ao mesmo tempo que possibilita o amadurecimento e comprometimento dos estudantes para atuar na prática, e isso impacta na qualidade da assistência prestada aos usuários.

No tocante às dificuldades, a pesquisa mostrou que existem divergências entre academia e serviço, reveladas principalmente pela valorização de diferentes conceitos, dificuldades em compatibilizar as agendas dos docentes e enfermeiros, pouco envolvimento docente com a prática, sobrecarga e despreparo do enfermeiro para atuar no ensino, além de falta de compreensão da equipe quanto ao papel do hospital de ensino.

Os participantes da pesquisa apresentaram sugestões de melhoria na integração academia-serviço, como a necessidade de avançar na ampliação dos espaços de diálogo, o maior envolvimento dos atores nos distintos cenários e decisões compartilhadas, e maior capacitação e valorização do profissional do serviço.

É importante salientar a complexidade que envolve a lógica de integração academia-serviço, considerando que nela se incluem sujeitos distintos pela formação, pela faixa etária e até mesmo pela valoração social, além 
de pertencerem a distintos cenários, que, embora sejam complementares para a formação profissional, possuem objetos de trabalho diferenciados.

Desse modo, depreende-se a necessidade de constante avaliação desse processo, com vistas a evidenciar as fragilidades e forças, o que possibilitará estratégias de intervenção para melhoria, considerando a sua relevância para a assistência e para a formação profissional em uma instituição que se propõe a tais fins que, incontestavelmente, precisam caminhar juntos.

\section{Colaboradores}

Os autores trabalharam em conjunto em todas as etapas da produção do manuscrito.

Resumen Este estudio se propone comprender la integración academia-servicio en la formación de enfermeros. Se utilizó la investigación cualitativa y, como referencia de análisis, la hermenéutica dialéctica. Fueron respondidos 24 cuestionarios por parte de docentes, enfermeros asistenciales y estudiantes de enfermería del cuarto año del curso de Enfermería de una institución de enseñanza superior, que cuenta con un complejo hospitalario habilitado como hospital de enseñanza. Se constató la existencia de espacios de encuentro entre los actores y la construcción del conocimiento a partir de la práctica, permitiendo el desarrollo del cuidado individual, colectivo y de gestión. La integración academia-servicio estimula a los profesionales del servicio a buscar conocimiento e investigación, y contribuye para los cambios en la práctica y en el compromiso de los estudiantes. Se encuentran dificultadas por la incompatibilidad de las agendas de docentes y enfermeros, poco compromiso docente con la práctica, sobrecarga y falta de preparación del enfermero para la enseñanza, además de la falta de comprensión del equipo multiprofesional en cuanto al papel del hospital de enseñanza. Se señala la necesidad de adecuación de las estructuras y la ampliación de los espacios de diálogo, con mayor compromiso y decisiones compartidas y, además, la calificación del profesional del servicio. Se desprende la necesidad de inversiones en la calificación del proceso de integración enseñanza y servicio.

Palabras clave servicios de integración docente-asistencial; formación de recursos humanos; hospitales de enseñanza; educación superior; estudiantes de enfermería. 


\section{Notas}

${ }^{1}$ Hospital das Clínicas da Faculdade de Medicina de Marília, Fragata, Marília, São Paulo, Brasil.

<patriciasales@famema.br>

Correspondência: Rua Tupinambás, 219, Aeroporto, CEP 17514-100, Marília, São Paulo, Brasil.

2 Faculdade de Medicina de Marília, Programa de Pós-Graduação em Ensino em Saúde, Curso de Enfermagem, Fragata, Marília, São Paulo, Brasil.

<marnadia@terra.com.br>

3 Faculdade de Medicina de Marília, Curso de Medicina, Fragata, Marília, São Paulo, Brasil.

<silvacr@famema.br >

4 Extraído da dissertação de mestrado intitulada Integração ensino-serviço: formação de enfermeiros em um hospital-escola, de Patrícia Regina de Souza Sales, apresentada ao Programa de Pós-Graduação Mestrado Profissional Ensino em Saúde da Famema. Parecer favorável do Comitê de Ética e Pesquisa com seres humanos da Famema n. 178/12. O estudo está livre de qualquer conflito de interesse.

\section{Referências}

ALBUQUERQUE, Verônica S. et al. A integração ensino-serviço no contexto dos processos de mudança na formação superior dos profissionais da saúde. Revista Brasileira de Educação Médica, Rio de Janeiro, v. 32, n. 3, p. 356-362, jul./set. 2008.

AYRES, José R. C. M. Hermenêutica e humanização das práticas de saúde. Ciência \& Saúde Coletiva, Rio de Janeiro, v. 10, n. 3, p. 549-560, jul./set. 2005.

BARATA, Luiz R. B.; MENDES, José D. V.; BITTAR, Olímpio J. N. V. Hospitais de ensino e o Sistema Único de Saúde. Revista de Administração em Saúde, São Paulo, v. 12, n. 46, p. 7-14, jan./mar. 2010.

BATISTA, Nildo et al. O enfoque problematizador na formação de profissionais da saúde.
Revista de Saúde Pública, São Paulo, v. 39, n. 2, p. 231-237, abr. 2005.

BRASIL. Assembleia Nacional Constituinte. Constituição do Brasil 1988. Rio de Janeiro: Bloch, 1988.

BRASIL. Ministério da Educação. Ministério da Previdência e Assistência Social. Portaria interministerial n. 15, de 22 de maio de 1987. Estabelece, no âmbito do convênio MEC/MPAS, critérios e parâmetros para a aplicação do Índice de Valorização de Desenvolvimento (IVD) e atribui o Índice de Valorização Hospitalar (IVH), de acordo com critérios, e dá outras providências. Diário Oficial da União, Brasília, DF, 26 maio 1987.

BRASIL. Presidência da República. Lei n. 8.080, de 19 de setembro de 1990. Dispõe 
sobre as condições para a promoção, proteção e recuperação da saúde, a organização e o funcionamento dos serviços correspondentes e dá outras providências. Brasília, 1990. Disponível em: <www.planalto.gov.br/ccivil_ 03/leis/l8080.htm>. Acesso em: 15 ago. 2012.

BRASIL. Ministério da Saúde. Secretaria de Gestão do Trabalho e da Educação em Saúde. Departamento de Gestão da Educação na Saúde. Política de educação e desenvolvimento para o SUS: polos de educação permanente em saúde Brasília, 2004. (Série C: Projetos, programas e relatórios).

BRASIL. Ministério da Saúde. Ministério da Educação. Programa Nacional de Reorientação da Formação Profissional em Saúde: Pró-Saúde. Brasília: Ministério da Saúde, 2005.

BRASIL. Ministério da Educação. Ministério da Saúde. Portaria interministerial n. 2.400, de 2 de outubro de 2007. Estabelece os requisitos para certificação de unidades hospitalares como hospitais de ensino. Diário Oficial da União, Brasília, DF, 3 de outubro de 2007. Seção 2, p. 26. Disponível em: <http:// dtr2001.saude.gov.br/sas/PORTARIAS/ Port2007/GM/GM-2400.htm>. Acesso em: 15 ago. 2012.

BRASIL. Ministério da Saúde. Secretaria de Gestão do Trabalho e da Educação na Saúde. Departamento de Gestão da Educação em Saúde. Política Nacional de Educação Permanente em Saúde. Brasília: Ministério da Saúde, 2009.

BRASIL. Ministério da Saúde. Secretaria de Atenção à Saúde. Departamento de Atenção Básica. Diretrizes do NASF: Núcleo de Apoio à Saúde da Família. Brasília, 2010. Disponível em: <http://bvsms.saude.gov.br/bvs/ publicacoes/diretrizes_do_nasf_nucleo.pdf $>$. Acesso em: 19 set. 2012.

CAETANO, Joselany A.; DINIZ, Rita C. M.; SOARES, Enedina. Integração docente-assistencial sob a ótica dos profissionais de saúde. Cogitare Enfermagem, Curitiba, v. 14, n. 4, p. 638-644, out./dez. 2009.
COLLISELLI, Liane et al. Estágio curricular supervisionado: diversificando cenários e fortalecendo a interação ensino-serviço. Revista Brasileira de Enfermagem, Brasília, v. 62, n. 6, p. 932- 937, nov./dez. 2009.

CUNHA, Maria I. Conta-me agora!: as narrativas como alternativas pedagógicas na pesquisa e no ensino. Revista da Faculdade de Educação, São Paulo, v. 23, n. 1/2, p. 185-196, jan./dez. 1997.

FACULDADE DE MEDICINA DE MARÍLIA. Projeto Pedagógico do Curso de Enfermagem. Marília: Famema, 2008.

FEUERWERKER, Laura C. M. Além do discurso de mudança na educação médica: processos e resultados. São Paulo: Hucitec, 2002.

FEUERWERKER, Laura C. M; COSTA, Heloniza; RANGEL, Maria L. Diversificação de cenários de ensino e trabalho sobre necessidade/problemas da comunidade. Divulgação em Saúde para Debate, Rio de Janeiro, n. 22, p. $36-48$, dez. 2000

FEUERWERKER, Laura C. M.; SENA, Rosení de. A construção de novos modelos acadêmicos, de atenção à saúde e de participação social. In: ALMEIDA, Marcio; FEUERWERKER, Laura C. M.; LLANOS C., Manuel (org.). A educação dos profissionais de saúde na América Latina: teoria e prática de um movimento de mudança. São Paulo: Hucitec, 1999. v. 1, p. 47-82.

FONTANELLA, Bruno J. B.; RICAS, Janete; TURATO, Egberto R. Amostragem por saturação em pesquisas qualitativas em saúde: contribuições teóricas. Cadernos de Saúde Pública, Rio de Janeiro, v. 24, n. 1, p. 17-27, jan. 2008.

FREIRE, Paulo. Educação como prática da liberdade. 29. ed. Rio de Janeiro: Paz e Terra, 2006.

GONÇALVES, Ernesto L. (org.). Administração de saúde no Brasil. São Paulo: Pioneira, 1982 . 
KISIL, Marcos. Uma estratégia para a reforma sanitária: a iniciativa UNI. Divulgação em Saúde para Debate, Londrina, n. 12, p. 5-14, jul. 1996.

LIMA, Jamile O. Uma estratégia para articulação ensino-serviço no SUS-BA: a rede de integração da educação e trabalho na saúde. Dissertação (Mestrado Profissional em Gestão do Trabalho e da Educação na Saúde) Escola Nacional de Saúde Pública Sérgio Arouca, Fiocruz, Rio de Janeiro, 2009.

LOBO, Maria S. C et al. Avaliação de desempenho e integração docente-assistencial nos hospitais universitários. Revista de Saúde Pública, São Paulo, v. 44, n. 4, p. 581-590, ago. 2010.

MACÊDO, Maria C. S. et al. Cenários de aprendizagem: interseção entre os mundos do trabalho e da formação. In: PINHEIRO, Roseni; CECCIM, Ricardo B.; MATTOS, Ruben A. (org.). Ensinar saúde: a integralidade e o SUS nos cursos de graduação na área da saúde. Rio de Janeiro: IMS/Uerj, Cepesq, Abrasco, 2005.

MALTA, Deborah C.; MERHY, Emerson E. O percurso da linha do cuidado sob a perspectiva das doenças crônicas não transmissíveis. Interface: Comunicação, Saúde, Educação, Botucatu, v. 14, n. 34, p. 593-606, jul./set. 2010.

MARCOLINO, Taís Q.; MIZUKAMI, Maria da Graça N. Narrativas, processos reflexivos e prática profissional: apontamentos para pesquisa e formação. Interface: Comunicação, Saúde, Educação, Botucatu, v. 12, n. 26, p. 541-547, jul./set. 2008.

MESTRINI JÚNIOR, Wilson et al. O desenvolvimento de competências em atenção básica à saúde: a experiência no projeto Huka-katu. Ciência \& Saúde Coletiva, Rio de Janeiro, v. 16, supl. 1, p. 903-912, 2011.

MINAYO, Maria C. S. (org.). Pesquisa social: teoria, método e criatividade. 19. ed. Petrópolis: Vozes, 2001.
MINAYO, Maria C. S. O desafio do conhecimento: pesquisa qualitativa em saúde. 8 . ed. São Paulo: Hucitec, 2004.

MOIMAZ, Suzely A. S. et al. Práticas de ensino-aprendizagem com base em cenários reais. Interface: Comunicação, Saúde, Educação, Botucatu, v. 14, n. 32, p. 69-79, jan./mar. 2010.

MORAIS, Fátima R. R. et al. A reorientação do ensino e da prática de enfermagem: implantação do Pró-Saúde em Mossoró, Brasil. Revista Gaúcha de Enfermagem, Porto Alegre, v. 31, n. 3, p. 442-449, set. 2010.

PEREIRA, Juliana G.; FRACOLLI, Lislaine A. Articulação ensino-serviço e vigilância da saúde: a percepção de trabalhadores de saúde de um distrito escola. Trabalho, Educação e Saúde, Rio de Janeiro, v. 9, n. 1, p. 63-75. mar./jun. 2011.

SILVA, Elisabete V. M. A formação de profissionais da saúde em sintonia com o SUS: currículo integrado e interdisciplinar. Brasília: Conselho Nacional de Secretarias Municipais de Saúde (Conasems); . Núcleo de Gestão do Trabalho e Educação na Saúde; Ministério da Saúde, 2008.

SOUZA, Luis E. P. F. O SUS necessário e o SUS possível: gestão: uma reflexão a partir de uma experiência concreta. Ciência \& Saúde Coletiva, Rio de Janeiro, v. 14, n. 3, p. 911-918, maio/jun. 2009.

VENDRUSCOLO, Carine et al. Planejamento situacional na Estratégia Saúde da Família: atividade de integração ensino-serviço na enfermagem. Revista Gaúcha de Enfermagem, Porto Alegre, v. 31, n. 1, p. 183-186, 2010.

Recebido em 15/03/2013

Aprovado em 11/02/2014 